\title{
RELIANCE AND CONTRACT BREACH
}

\author{
Jim Leitzel* \\ I \\ INTRODUCTION
}

Actions taken in reliance on a contract, and court protection of such reliance in the event of a breach, have been analyzed from both legal and economic perspectives. ${ }^{1}$ This article compares the legal and economic approaches to contractual reliance and develops a model for examining the protection of expenditures in reasonable reliance. The protection of reasonable reliance potentially involves circular arguments: Courts will protect the amount of reliance in which a reasonable person would engage, but a reasonable person would rely up to the extent that courts will protect. ${ }^{2}$ This article shows that the protection of reasonable reliance may be well defined, despite the potential circularity.

The economic analysis that has been done on contractual reliance has noted that the protection of reliance expenditures, in the event of a breach, may render such expenditures riskless from the viewpoint of the party engaging in the reliance. ${ }^{3}$ Since reliance expenditures are inherently risky, their protection may result in overreliance from society's point of view. ${ }^{4}$ Overreliance can be avoided if contractual damages are invariant with respect to reliance. ${ }^{5}$ Damage "measures can be interpreted as invariant with respect to reliance by limiting recovery on the basis of reliance to costs that are reasonably incurred."6 This interpretation of damages, however, is subject to the circularity problem inherent in reasonableness standards.

This article uses the bilateral contract ${ }^{7}$ as the context for the examination of reliance. This article focuses on the different answers provided by the

Copyright $\odot 1989$ by Law and Contemporary Problems

* Visiting Associate Professor of Economics, Duke University. An earlier version of this article was presented at Emory University. I would like to thank Jim Baer and Bradley Mindlin for helpful comments. Errors remain the responsibility of the author.

1. See Cooter \& Eisenberg, Damages for Breach of Contract, 73 Calif. L. REv. 1432 (1985); Fuller \& Perdue, Reliance Interest in Contract Damages: 1, 46 YALE L.J. 52 (1936); Kornhauser, Reliance, Reputation, and Breach of Contract, 26 J. L. EcoN. 691 (1983); Rogerson, Efficient Reliance and Damage Measures for Breach of Contract, 15 Rand J. ECON. 39 (1984); Shavell, Damage Measures for Breach of Contract, 11 BeLL J. ECoN. 466 (1980).

2. See Fuller \& Perdue, supra note 1 , at 85 (noting the circularity of reasonable man standards).

3. Rogerson, supra note 1, at 47; Shavell, supra note 1 , at 480.

4. If it is assumed that reliance expenditures are only beneficial when the contract is completed, then a breach implies a loss to society.

5. R. Cooter \& T. Ulen, LAW and EConomics 316 (1988); Cooter \& Eisenberg, supra note 1, at 1467; Leitzel, Damage Measures and Incomplete Contracts, 20 RAND J. ECON. 92, 98 (1989).

6. Cooter \& Eisenberg, supra note 1, at 1467.

7. In a bilateral contract, both parties make an offer, whereas in unilateral or donative contracts there is a promise by only one of the parties. E. Farnsworth, Contracts 109 (1982). Reliance 
economic as well as the legal approaches to three questions: (1) What constitutes a reliance action?; (2) How are reliance actions protected in the event of a breach of contract?; and (3) What information is necessary for contracting over and protecting reliance expenditures?

This article then presents a model of contracting that will aid in interpreting the legal and economic answers to the questions presented above. The model is also used to examine, in detail, the possibility of protecting only efficient levels of reliance, thus eliminating the incentive for overreliance. The article will also show that the circularity problem in the development of a reasonableness standard is not intractable, and that the courts are able to protect only reasonable reliance consistently.

\section{Descriptions of Reliance}

\section{A. Legal Descriptions}

A formal definition of reliance is not often included in the legal discussions of the issue. Usually, the term "reliance interest," rather than "reliance," is defined, with the definition often incorporating the common usage of reliance. "[T]he reliance interest represents the detriment that plaintiff has incurred by changing his position in reliance on his belief that defendant would fulfill his part of the bargain." 8 Although two categories of reliance are spelled out in some detail, a general definition of reliance does not appear in Fuller and Perdue's seminal legal treatise on reliance. ${ }^{9}$ The first category that Fuller and Perdue discuss is "essential reliance," in which the seller typically engages. ${ }^{10}$ Fuller and Perdue define essential reliance as:

[c]ertain acts of reliance [which] are in a loose sense the "price" of whatever benefits the contract may involve for the plaintiff. This type of reliance we shall call "essential reliance." Under this heading would be included the ... preparations to perform ... and the losses involved in entering the contract itself, as, for instance, in foregoing the opportunity to enter into other profitable contracts. ${ }^{11}$

The second category of reliance is labeled "incidental reliance," which is typically engaged in by the buyer.

In contrast to "essential reliance" is the kind of reliance involved in Nurse v. Barms, which we shall call "incidental reliance." The plaintiff's reliance there (laying in a stock of goods) followed naturally, and, we may assume, foreseeably, from the contract. It did not, however, consist of acts necessary to the perfection of the

actions also play an important role in unilateral or donative contracts. Reasonable reliance may make such contracts enforceable, even in the absence of consideration, through the doctrine of promissory estoppel. See, e.g., A. Corbin, Corbin on Contracts 277 (1952).

8. J. Friedman, Contract Remedies in a Nutshell 2 (1981). The Restatement (Second) states that "[a] reliance interest, include[s] expenditures made in preparation or in performance, less any loss that the party in breach can prove with reasonable certainty the injured party would have suffered had the contract been performed." RESTATEMENT (SECOND) OF ConTRACTS $\$ 349$ (1979).

9. See Fuller \& Perdue, supra note 1, at 78.

10. The reliance is "essential" in that the contract could not be performed without it. Since the buyer's contractual duty is often simply to pay for the good, essential reliance generally refers to the seller's actions in procuring the good.

11. Fuller \& Perdue, supra note 1 , at 78. 
plaintiff's rights on the contract; it cannot be regarded as the "price" of the defendant's performance. ${ }^{12}$

\section{B. Economic Descriptions}

In contrast to the legal analysis of contract law, economic analysis generally discusses reliance directly and the reliance interest only implicitly. ${ }^{13}$ The definitions of reliance that economists offer in their work closely echo the usage of the term in legal writings. Economists tend, however, to further highlight the transaction-specific nature of reliance by noting that reliance will be a losing investment for the relying party in the event of a contractual breach if damage payments are not made. An early paper utilizing an economic analysis of contractual breach offered this description:

If the transaction fails during performance, each party may be stuck with unrecoverable costs. The seller's partially completed goods may be valueless except as scrap. This possible loss is seller's reliance, or, in Fuller's vocabulary, essential reliance. Similarly, the buyer may have incurred expenditures-such as printing of packages-that become losses now that the contract has failed. These are buyer's reliance, or, in Fuller's vocabulary, incidental reliance. ${ }^{14}$

Recent economic analysis places even more stress on the contract-specific nature of the investment while the distinction between essential and incidental reliance is less often made (and quite often may play no role in the modeling). ${ }^{15}$

When economists introduce reliance into their models of contracting, the definitions of reliance that they offer tend to be more restrictive than those found in the legal literature. For example, reliance in the legal definition is not generally profitable in the event of contractual performance. This is true for two reasons. First, expenditures on reliance may occur before other events that may diminish the value of the expenditures. Second, contracts may be contingent, and are necessarily incomplete. This incompleteness may cause some actions that constitute performance to result in a loss of the benefits that were anticipated from the reliance expenditures. Alternatively, the models for contracts often used by economists involve perfectly specified actions in non-contingent contracts, and the benefit from reliance is not directly dependent on the realization of uncertainty. ${ }^{16}$ Because the economic definitions of reliance reflect these restrictions on the forms of contracts, results based on such restrictive views of reliance may not apply to the more general notions of reliance found in the legal literature.

12. Id. See Nurse v. Barns, 83 Eng. Rep. 43 (K.B. 1664).

13. Rogerson, supra note 1, at 39; Shavell, supra note 1, at 470.

14. Barton, The Economic Basis of Damages for Breach of Contract, I J. LeGal STud. 277, 280 (1972).

15. "Reliance is an investment that is profitable only in the event that performance occurs." Kornhauser, supra note 1, at 693. "Buyers or sellers must engage in expenditures before the date of exchange either to prepare to use the product or to prepare to sell it. (Lawyers call such expenditures reliance.) ... The value of reliance to the buyer or the seller is to some extent specific to the relationship between them." Rogerson, supra note 1 , at 39 .

16. Many of the economic models are structured this way. See, e.g., Rogerson, supra note 1; Shavell, supra note 1. 
III

\section{The Protection of Reliance}

\section{A. Discussion}

The reliance interest in a contract is protected directly by the reliance damage measure, and indirectly by the expectation damage measure. The reliance damage measure is designed to put the injured party in the same position in which she would have been had the contract never been entered into. ${ }^{17}$ Alternatively, the expectation damage measure is designed to put the injured party in the same position that she would have achieved had the contract been complied with. ${ }^{18}$ In other words, while the reliance damage measure protects a party's reliance investments, the expectation damage measure awards the injured party the benefit of the bargain. ${ }^{19}$

There are striking differences between the legal and economic treatments of the protection of reliance expenditures with respect to both the expectation and reliance damage measures. Economists have noted how the protection of reliance makes such actions riskless from the viewpoint of the party engaging in the reliance. ${ }^{20}$ Since reliance actions will prove unprofitable in the event of a breach, and since there is usually a positive probability of a breach, ${ }^{21}$ reliance actions are not riskless from society's point of view. Hence, damage measures that protect all reliance expenditures create an incentive for the parties to rely more than is socially optimal. ${ }^{22}$ The relative efficiency of the various damage measures is greatly influenced by this tendency toward overreliance caused by the overprotection given to the party making the reliance expenditures. ${ }^{23}$

In contrast, the legal writers often stress that only reliance that is reasonable, generally in the sense of being foreseeable, will be protected under the expectation and reliance damage measures. ${ }^{24}$ This method parallels the treatment of the expectation interest that originated with Hadley $v$. Baxendale. ${ }^{25}$ This reasonableness requirement of reliance protection militates against the incentives to overrely on contractual agreements. The

17. "Under the reliance measure, the defaulting party compensates the other party for his reliance expenditures and returns to the other party payments that he made. Therefore, except for foregone opportunities, the victim of breach is put back into the position he was before he entered the contract." Shavell, supra note 1 , at 471 .

18. Id.

19. The payment of reliance damages along with an award of expectation damages would, by definition, award the injured party the benefit of the bargain and also pay his reliance expenditures. This would be a duplicative award because, had the contract been completed, the injured party would have necessarily paid his own reliance expenditures. J. Friedman, supra note 8, at 107.

20. The freedom from risk to the party engaging in the reliance expenditures will only be up to the level of the protection.

21. Having a positive probability of a breach merely indicates that breach is a possibility. If the probability of a breach were zero, performance would be certain.

22. Rogerson, supra note 1, at 49; Shavell, supra note 1, at 472.

23. Rogerson, supra note 1, at 49; Shavell, supra note 1, at 472 .

24. The reasonableness requirement is also built into the doctrine of promissory estoppel. See, e.g., Restatement (Second) of Contracts $\$ 90(1)$ (1979).

25. Hadley v. Baxendale, 156 Eng. Rep. 145 (Ex. 1845). 
legal position was stated in Fuller and Perdue's work: "[W] of Hadley $v$. Baxendale as it arises inside the reliance interest itself? Should we refuse to grant compensation for acts of reliance where they are not 'proximately caused' by the contract, or were not 'reasonably foreseeable' by the promisor?"'26 The answer provided by Fuller and Perdue is that, with respect to essential reliance, the problem of reasonableness will not arise, ${ }^{27}$ but " $[\mathrm{a}] \mathrm{s}$ to incidental reliance the case is entirely different . . . . It would be impossible to deal adequately in this place with the ways in which courts have solved this problem. Here . . . the talk is primarily of foreseeability and notice."28 This conclusion has recently been re-emphasized. "Both the expectation and reliance measures undoubtedly contemplate that only reasonable reliance will be compensated. The question for present purposes is, 'What kind of factors determine reasonability?' '"29

A formalization of the expectation and reliance damage measures that protect only reasonable reliance is applied in the model of contracting constructed below. ${ }^{30}$ This approach was foreshadowed by Cooter and Eisenberg when they stated:

The [overreliance] problem can be avoided, however, if the reliance and expectation measures can be interpreted [so] as to provide for invariant damages with respect to reliance .... [T] he reliance and expectation measures can be interpreted as invariant with respect to reliance by limiting recovery on the basis of reliance to costs that are reasonably incurred. ${ }^{31}$

What is reasonable reliance, or equivalently, by what standard is overreliance to be judged? The obvious economic answer is that reasonable reliance is socially efficient reliance. Therefore, the socially efficient level of reliance will be the standard by which overreliance is judged in the analysis below. ${ }^{32}$

The major difficulty with protecting only reasonable reliance-the problem of circularity-was also foreshadowed in the legal literature:

As in the case of all "reasonable man" standards there is an element of circularity about the test of foreseeability. "For what items of damage should the court hold the defaulting promisor? Those which he should as a reasonable man have foreseen. But what should he have foreseen as a reasonable man? Those items of damage for which the court feels he ought to pay." 33

26. Fuller \& Perdue, supra note 1 , at 86.

27. The problem will not arise with essential reliance because such reliance is necessary for the completion of the contract. Therefore, such reliance is foreseeable.

28. Fuller \& Perdue, supra note 1 , at 88.

29. Cooter \& Eisenberg, supra note 1, at 1467. This quotation occurs in a much fuller discussion of the protection of reliance which does not entirely dismiss the possibility of overreliance.

30. The formalization is drawn from Leitzel, supra note 5 , at 97 .

31. Cooter \& Eisenberg, supra note 1, at 1467.

32. Both Rogerson and Shavell employ this standard in their analyses of reliance. Rogerson, supra note 1, at 44; Shavell, supra note 1, at 475.

33. Fuller \& Perdue, supra note 1 , at 85. 


\section{B. A Contract Model}

In constructing the economic model, it is assumed that a bilateral contract is entered into by two risk-neutral parties. ${ }^{34}$ An example is a contract where a risk-neutral buyer buys a good at a specified price from a risk-neutral seller. ${ }^{35}$ After the contract is entered into, but before the uncertainty is realized and the contract-related actions are chosen, the buyer ${ }^{36}$ chooses a reliance position $r{ }^{37}$ All reliance actions taken by the buyer will result in the buyer making monetary expenditures. ${ }^{38}$

Once the reliance position has been chosen by the buyer, the outcome of all uncertainty in the contracting environment will be realized. ${ }^{39}$ A realization $\theta$ will resolve all uncertainties for the contracting parties except for contractrelated actions and damage payments. Though the parties do not know the realization of the uncertainty when the contract formation is taking place, both parties know that the probability distribution function over the possible status of the uncertainty is $F \theta$.

Upon the realization of $\theta$, the seller ${ }^{40}$ chooses either to deliver the good and complete the contract, or not to deliver the good and breach the contract. The seller's decision of whether to complete or breach the contract will be noted by the variable $a$. When $a$ is equal to $a_{1},\left(a=a_{1}\right)$, it implies that the seller has completed the contract. In contrast, if $a$ is equal to $a_{2}\left(a=a_{2}\right)$, it implies that the seller has decided to breach the contract.

The monetary outcome of the contract to both parties is determined by the action that the seller takes, the reliance expenditures by the buyer, and the realization of the uncertainty. The function $x_{b}{ }^{\prime}\left(a_{1}, r\right)^{41}$ is a mapping that represents buyer's utility exclusive of damage payments. ${ }^{42}$ Similarly, $x_{s}{ }^{\prime}\left(a_{i}, \Theta\right)$ represents seller's utility exclusive of damages. The utility functions of the parties incorporate the assumption that the buyer's preferences are not directly state-dependent and that the seller's preferences do not depend on the buyer's reliance expenditures.

34. The assumption that both parties are risk-neutral is for the purpose of examining contracts free from risk allocation. See Rogerson, supra note 1, at 41.

35. The agreed upon price is immaterial to the analysis. Price simply allocates the joint surplus of the contract between the risk-neutral parties.

36. Either or both of the parties can make reliance expenditures. See Shavell, supra note 1, at 474. To simplify the model, it is assumed that only the buyer relies.

37. The available set $R=[0, \tilde{r}]$ of reliance actions includes $r$ as an element. The closed set $[0, \bar{r}]$ is a subset of the non-negative real line $R_{+}$. Therefore, reliance expenditures are non-negative and finite.

38. This assumption does not rule out non-monetary reliance actions as long as they have monetary equivalents.

39. The set of possible states of the uncertainty is $\Theta=\left\{\theta_{1}, \theta_{2}, \ldots, \theta_{m}\right\}$, where each $\theta_{i}, i=1$, $\ldots, \mathrm{m}$, is a realization of the uncertainty.

40. As with reliance expenditures, either party generally has the ability to breach the contract. For purposes of analysis, it will be assumed that only the seller has the ability to make the decision whether to breach or to perform.

41. Both seller's and buyer's utility functions are von Neumann-Morgenstern utility functions.

42. Damage payments will be introduced into the model at a later stage. 
ASSUMPTION A 1:

(i) $x_{b}{ }^{\prime}\left(a_{1}, r\right)$ is increasing in $r$ for $r \in[0, \hat{r}]$, and is decreasing in $r$ for $r \in[\hat{r}, \vec{r}]$;

(ii) $x_{b}{ }^{\prime}\left(a_{2}, r\right)$ is decreasing in $r$;

(iii) $x_{b}{ }^{\prime}\left(a_{1}, r\right)>x_{b}{ }^{\prime}\left(a_{2}, r\right)$ for all $r \in R$.

Assumption Al(i) indicates that, if the seller is certain to comply with the contractual terms, the buyer will have a finite and unique optimal level of reliance, $\hat{\mathbf{r}}$. Any expenditure over $\hat{\mathbf{r}}$ will decrease the buyer's utility. Assumptions Al (ii) and Al(iii) formalize the transaction-specific nature of the reliance expenditures by stating that, if the contract is breached, reliance does not pay. Further, no matter how much the buyer spends on reliance, she will always prefer (exclusive of damage payments) the completion of the contract over a seller's breach. Assumption Al indicates that the more restrictive economic interpretation of reliance will be employed rather than the legal definition.

When the seller makes the decision whether to breach or to complete the contract, he is able to observe both the level of reliance $r^{\prime}$ and the state realization $\theta$. With this information, the socially efficient seller action, $a^{*}\left(r^{\prime}\right.$, $\theta)$, is determined by the problem: ${ }^{43}$

$$
\text { (1) } a^{*}\left(r^{\prime}, \theta\right)=\underset{a^{\prime} \epsilon}{\operatorname{argmax}}\left\{a_{1}, a_{2}\right\} x_{s}{ }^{\prime}\left(a^{\prime}, \theta\right)+x_{b}{ }^{\prime}\left(a^{\prime}, r^{\prime}\right) \text {. }
$$

Using the socially efficient seller actions with respect to all levels of the buyer's reliance, the socially efficient level of buyer's reliance $r^{*}$ can be determined. If the expectation operator taken with respect to $F(\theta)$ is $E(\cdot)$, then $r^{*}$ is determined by the problem:

$$
(2) r^{*}=\underset{r^{\prime} \in R}{\operatorname{argmax}} E\left[x_{b}{ }^{\prime}\left(a^{*}\left(r^{\prime}, \theta\right), r^{\prime}\right)+x_{s}{ }^{\prime}\left(a^{*}\left(r^{\prime}, \theta\right), \theta\right)\right] .^{44}
$$

To achieve the socially efficient contract outcome, the buyer must choose reliance level $r^{*}$, and the seller must choose actions $a^{*}\left(r^{*}, \theta\right)$.

Lemma 1: The socially efficient level of reliance, $r^{*}$, is less than or equal to the buyer's optimal reliance level, $\hat{\mathbf{r}}$, given seller's action $a_{1}{ }^{45}$

In the model so far, the seller generally will not have any incentive to take the socially efficient actions. However, should the seller choose to breach, he will have to pay damages to the buyer. The amount of damages is given by the damage measure $\delta(\cdot)$. The final payoff to the seller is thus $x_{s}(a, \theta, \delta)=$ $x_{s^{\prime}}(a, \theta)-\delta$, while the buyer's final contract payoff is $x_{b}(a, r, \delta)=x_{b}{ }^{\prime}(a, r)$ $+\delta .46$ The damage payment for breach of the contract will prevent the seller

43. It is assumed that no third parties are affected by the contract, so that social efficiency is equivalent to maximizing the joint payoffs of the risk-neutral buyer and seller.

44. The solutions to (1) and (2) are taken to be unique. The socially efficient actions are independent of any damage measure because, like the contract price, damages simply act to redistribute the contract surplus.

45. For a proof of Lemma 1, see Appendix A infra.

46. For all damage measures, damage payments are taken to be zero if the seller chooses $a_{1}$. Payoffs $x_{1}(a, \theta, \delta)$ and $x_{b}(a, r, \delta)$ are von Neumann-Morgenstern utilities. 
from totally ignoring the effect of his action on the buyer's utility. As defined above, two important damage measures are the expectation damage measure, $\delta_{E}$, and the reliance damage measure, $\delta_{R}$. If the buyer's reliance level is $r$, a breaching seller subject to the expectation damage measure will have to pay damages given by:

$$
\text { (3) } \delta_{E}=x_{b}{ }^{\prime}\left(a_{1}, r\right)-x_{b}{ }^{\prime}\left(a_{2}, r\right) .{ }^{47}
$$

Reliance damages will be determined by:

$$
\text { (4) } \delta_{R}=\overline{x_{b}}{ }^{\prime}-x_{b}{ }^{\prime}\left(a_{2}, r\right)
$$

where $\overline{x_{b}}$ 'is the utility that the buyer would have achieved in the absence of the contract. ${ }^{48}$

Given the damage measures, it is possible to compare the actual contractual outcome with socially efficient reliance and the action decisions that were formulated above. Actual contractual choices may differ from the socially efficient choices since the seller chooses his action non-cooperatively. That is, the seller chooses whether to complete the contract without taking into account (beyond the payment he must make for damages) the effect that his action will have on the buyer. Likewise, the buyer will choose her reliance action non-cooperatively. That is, the buyer will choose a level of reliance without taking into account the potentially adverse effect that her reliance expenditures may have on the seller through the damage measures. So, given reliance $r$, state realization $\theta$, and damage measure $\delta$, the seller will choose action $a(\mathrm{r}, \theta, \delta)$ by:

$$
\text { (5) } a(r, \theta, \delta)=\underset{a^{\prime} \epsilon}{\operatorname{argmax}}\left\{a_{1}, a_{2}\right\} x_{s}^{\prime}\left(a^{\prime}, \theta\right)-\delta(\cdot ; r)
$$

Understanding how the seller will choose $a(\cdot)$, the buyer will choose a reliance level $r$ by:

$$
\text { (6) } r=\underset{r^{\prime} \in R}{\operatorname{argmax}} E\left[x_{b}^{\prime}\left(a\left(r^{\prime}, \theta, \delta\right), r^{\prime}\right)+\delta(\cdot ; r)\right] \text {. }
$$

It is well known that the expectation damage measure as defined above will result in an identical solution to equations (1) and (5). Therefore, given buyer's reliance level, the expectation damage measure will induce the seller to make the socially efficient breach decisions. ${ }^{49}$ In contrast to the expectation damage measure, the reliance damage measure will result in excessive breach given the buyer's level of reliance. ${ }^{50}$ The different outcomes

47. Equation (3) states that the expectation damage measure, $\delta_{E}$, equals the difference between the payoff that the buyer would have achieved had the contract been performed, $x_{b}{ }^{\prime}\left(a_{1}, r\right)$, less the payoff that the buyer has due to the breach, $x_{b}\left(a_{2}, r\right)$. The buyer will receive the benefit of her bargain.

48. Equation (4) states that the reliance damage measure, $\delta_{R}$, equals the difference between the buyer's payoff had the contract not been entered into, $\overline{x_{b}}$, less the buyer's payoff after'a breach, taking into consideration her reliance expenditures.

49. See, e.g., Shavell, supra note 1 , at 478. Using equation (5), and substituting $\delta_{\mathrm{E}}$ for $\delta$, the seller will choose to breach with $a_{2}$ if $x_{s}^{\prime}\left(a_{2}, \theta\right)-x_{b}^{\prime}\left(a_{1}, r\right)+x_{b}^{\prime}\left(a_{2}, r\right)>x_{s}^{\prime}\left(a_{1}, \theta\right)$. Rearranging this expression, the seller will choose to breach if $x_{s}{ }^{\prime}\left(a_{2}, \theta\right)+x_{b}{ }^{\prime}\left(a_{2}, r\right)>x_{x}{ }^{\prime}\left(a_{1}, \theta\right)+x_{b}{ }^{\prime}\left(a_{1}, r\right)$, which is the criterion for efficient breach from equation (1). If the seller has more than two potential actions, the expectation damage measure will still provide for efficient breach, although inefficient actions that comply with the terms of the (incomplete) contract still may be taken. See Leitzel, supra note 5 , at 99.

50. See, e.g., Shavell, supra note 1 , at 479 . This can be seen by substituting equation (4) into equation (5) and simplifying. Seller will breach whenever $x_{s}^{\prime}\left(a_{2}, \theta\right)-\bar{x}_{b}^{\prime}+x_{b}\left(a_{2}, r\right)>x_{s}^{\prime}(a, \theta)$. 
are due to the fact that, while the second terms of the $\delta_{E}$ and $\delta_{R}$ damage measures are the same, the first term of $\delta_{E}, x_{b}{ }^{\prime}\left(a_{1}, r\right)$, generally exceeds the first term of $\delta_{R},{\overrightarrow{x_{b}}}^{\prime}$. This is necessarily true, since the buyer would not enter into a contract if the performance of the contract would not increase the buyer's utility. ${ }^{51}$

Knowing what the seller's action choices under $\delta_{E}$ and $\delta_{R}$ will be, the problem is to determine how much the buyer will expend on reliance. Under expectation damages, $\delta_{E}$, the buyer will achieve the same benefits, $x_{b}{ }^{\prime}\left(a_{1}, r\right)$, regardless of the seller's choice to perform or breach. Buyer will therefore choose the level of reliance that will optimize her outcome as if she knew that the seller would perform the contract. But the buyer's optimal level of reliance, given that the seller will choose $a_{1}$, is $\hat{\mathbf{r}} .{ }^{52}$ Hence, even given efficient breach behavior by the seller, Lemma 1 implies that the buyer will generally expend too much on reliance when the expectation damage measure governs. Under the reliance damage measure $\delta_{R}$, the buyer's payoff will be $x_{b}{ }^{\prime}\left(a_{1}, r\right)$ if the seller does not breach, and $\overline{x_{b}}{ }^{\prime}$ (independent of $r$ ) if the seller chooses to breach. Since the seller determines his action by, among other factors, buyer's reliance level, the buyer can increase the likelihood that the seller will not breach by increasing her reliance expenditures. This is true because, if the buyer increases her reliance level, Assumption Al(ii) and the definition of reliance damages, $\delta_{R}$, imply that he will be increasing the damage payments due him if the seller decides to breach. Since the buyer is always better off if the seller completes the contract, Assumption Al(iii), the buyer will encourage the seller to complete the contract by increasing reliance damage payments. So, as with $\delta_{E}$, under the reliance damage measure the buyer will choose a reliance level $r$ such that $r \geq r^{*} .{ }^{53}$ This overreliance by the buyer results from the protection under $\delta_{E}$ and $\delta_{R}$ of all reliance, instead of simply protection up to the efficient level.

Consider reformulating the expectation and reliance damage measures to eliminate the incentives for overreliance. ${ }^{54}$ Given damage measure $\delta$, the " $\delta$ efficient level of reliance" will be defined as $r^{*}(\delta)$, to be determined by:

$$
(7) r^{*}(\delta)=\underset{r^{\prime} \in R}{\operatorname{argmax}} E\left[x_{b}{ }^{\prime}\left(a\left(r^{\prime}, \theta, \delta\right), r^{\prime}\right)+x_{s}{ }^{\prime}\left(a\left(r^{\prime}, \theta, \delta\right), \theta\right)\right],
$$

where actions $a\left(r^{\prime}, \Theta, \delta\right)$, are given by equation (5). Thus, the $\delta$-efficient level of reliance takes into account that the seller, when determining his actions, will choose those actions non-cooperatively given the damage measure $\delta$. The solution to equation ( 7 ) consists of the best cooperative level of reliance, in terms of social welfare, that the buyer could choose given the constraint.

51. But see infra Part IV.

52. This follows from Assumption Al(i).

53. These arguments and results are given in Rogerson, supra note 1, at 49; Shavell, supra note 1 , at 478 .

54. For suggestions of such a reformulation, see $R$. Cooter \& T. Ulen, supra note 5, at 309; Cooter and Eisenberg, supra note I, at 1462; Leitzel, supra note 5, at 97. 
Now the expectation and reliance damage measures can be amended to protect only for an appropriate $\delta$-efficient level of reliance:

$$
\begin{aligned}
& \delta_{E}^{\prime}=\left\{\begin{array}{l}
x_{b}{ }^{\prime}\left(a_{1}, r^{*}\left(\delta_{E}{ }^{\prime}\right)\right)-x_{b}{ }^{\prime}\left(a_{2}, r^{*}\left(\delta_{E}{ }^{\prime}\right)\right), \text { for } r>r^{*}\left(\delta_{E}{ }^{\prime}\right) \\
x_{b}{ }^{\prime}\left(a_{1}, r\right)-x_{b}{ }^{\prime}\left(a_{2}, r\right), \text { for } r \leq r^{*}\left(\delta_{E}{ }^{\prime}\right) ; \text { and }
\end{array}\right. \\
& \delta_{R}^{\prime}=\left\{\begin{array}{l}
\overline{x_{b}}-x_{b}{ }^{\prime}\left(a_{2}, r^{*}\left(\delta_{R}{ }^{\prime}\right)\right), \text { for } r>r^{*}\left(\delta_{R}{ }^{\prime}\right) \\
\overline{x_{b}}-x_{b}{ }^{\prime}\left(a_{2}, r\right), \text { for } r \leq r^{*}\left(\delta_{R}{ }^{\prime}\right) .
\end{array}\right.
\end{aligned}
$$

These definitions are obviously self-referential. ${ }^{55}$ It may be possible, however, to overcome this circularity with a "fixed point argument." 56 For example, assume that the court announces that it will protect, under $\delta_{E}$, the level of reliance $\tilde{\mathrm{r}}$. Then, using $\tilde{\mathrm{r}}$ in applying $\delta_{\mathrm{E}}$, calculate the $\delta_{E}{ }^{\prime}(\tilde{r})$-efficient level of reliance from equation (7). Repeating this process for all $\tilde{r} \in R$ produces a $\delta_{E}{ }^{\prime}(\tilde{r})$-efficient level of reliance for each level of reliance $\tilde{\mathrm{r}}$ that the court is willing to protect-in other words, a mapping from $R$ to $R$. By defining the actual $\delta_{E}{ }^{\prime}$-efficient level of reliance $\tilde{r}^{*}\left(\delta_{E}{ }^{\prime}\right)$ to be a fixed point of this mapping (that is, $\tilde{r}=r^{*}\left(\delta_{\mathrm{E}}{ }^{\prime}(\tilde{r})\right)$, the level of reliance that the court is willing to protect will also be the $\delta_{E}{ }^{\prime}(\tilde{r})$-efficient level. The $\delta_{E}{ }^{\prime}$-efficient level of reliance can also be similarly defined as such a fixed point.

There may be multiple fixed points to the reliance mapping, or there may be none. There will be, however, one focal candidate for the $\delta_{E}$ '-efficient level of reliance. That candidate will be the socially efficient level of reliance, $r^{*}$, as defined in equation (2).

Proposition 1: The socially efficient level of reliance $r^{*}$ is a fixed point in calculating the $\delta_{E}{ }^{\prime}$-efficient level of reliance. ${ }^{57}$

There may be other fixed points of the reliance mapping, but the $\delta_{E}{ }^{\prime}$-efficient level of reliance can always be taken to be $r^{*}$, the socially efficient level. This definition of the $\delta_{E}{ }^{\prime}$-efficient level of reliance presents the immediate result:

Proposition 2: The seller's actions and the buyer's reliance under $\delta_{\mathrm{E}}$ ' will be socially efficient. ${ }^{58}$

The socially efficient level of reliance always serves as the $\delta_{\mathrm{E}}{ }^{\prime}$-efficient level of reliance since expectation damages induce efficient breach, given reliance. Reliance damages do not induce efficient breach, so no such obvious candidate as $r^{*}$ exists for the $\delta_{\mathrm{R}}$ '-efficient level of reliance for all contract problems. The example in the following section illustrates the arguments of this section in a concrete case. In addition, the example will also indicate how the $\delta_{R}{ }^{\prime}$ efficient level of reliance may be determined.

55. Fuller \& Perdue, supra note 1 , at 85.

56. See J. Henderson \& R. Quandt, Microeconomic Theory: A Mathematical Approach 258 (3d ed. 1980); Leitzel, supra note 5, at 97.

57. For a proof of Proposition 1, see Appendix B infra.

58. For a proof of Proposition 2, see Appendix C infra. 


\section{Example}

It will be assumed that the uncertainty is represented by a uniform distribution of $\theta$ on $[0,1]$. The set of potential buyer reliance actions is given by the unit interval $R=[0,1]$. The buyer's utility level is $\overline{x_{b}}=.25$ if the contract is never entered into by the parties. The seller's preferences over actions and states, and the buyer's preferences over actions and reliance, are given by:

$$
\begin{gathered}
x_{s}{ }^{\prime}\left(a_{1}, \theta\right)=-2 \Theta \\
x_{s}{ }^{\prime}\left(a_{2}, \theta\right)=0 \\
x_{b}{ }^{\prime}\left(a_{1}, r\right)=5 r-5 r^{2} \\
x_{b}{ }^{\prime}\left(a_{2}, r\right)=-0.5 r .
\end{gathered}
$$

Thus, higher realizations of $\theta$ make it more costly for the seller to perform, while non-performance results in losses to the buyer's reliance. Note that Assumption $\mathrm{Al}$ is met, and that:

$$
\hat{r}=\underset{r^{\prime} \in R}{\operatorname{argmax}} x_{b}{ }^{\prime}\left(a_{1}, r^{\prime}\right)=\underset{r^{\prime} \in R}{\operatorname{argmax}} 5 r^{\prime}-5\left(r^{\prime}\right)^{2}=.5 .
$$

1. The Socially Efficient Outcome. Given the level of reliance $r$, the socially efficient choice for the seller's action is to breach in state $\Theta$ if:

(8) $x_{s}{ }^{\prime}\left(a_{2}, \theta\right)+x_{b}{ }^{\prime}\left(a_{2}, r\right)>x_{s}{ }^{\prime}\left(a_{1}, \theta\right)+x_{b}{ }^{\prime}\left(a_{1}, r\right)$.

In this example, the condition for efficient breach becomes $-0.5 r>-2 \theta+$ $5 r-5 r^{2}$. The seller will breach when $\theta>(11 / 4) r-(5 / 2) r^{2}$. Denote this critical value of $\theta$ as $\theta^{\prime}$. The socially efficient level of reliance, $r^{*}$, is then given by:

$$
\begin{gathered}
\underset{r^{\prime} \in R}{\operatorname{argmax}}\left[\operatorname{Pr}\left\{0 \leq \theta \leq \theta^{\prime}\right\}\right]\left(E\left[-2 \theta+5 r-5 r^{2} \mid 0 \leq \theta \leq \theta^{\prime}\right)\right. \\
+\left[\operatorname{Pr}\left\{\theta^{\prime}<\theta \leq 1\right\}\right](-.5 r) .
\end{gathered}
$$

The solution to this problem is, approximately, $r^{*}=.483$, with a corresponding critical state realization $\theta^{\prime}=.745 .59$ This signifies that, if the parties would behave in a socially efficient manner, the buyer's reliance level will be $r=.483$, and the seller will breach only if the state realization is such that $\theta>.745$.

2. Contracting under $\delta_{E}=x_{b}{ }^{\prime}\left(a_{1}, r\right)-x_{b}{ }^{\prime}\left(a_{2}, r\right)$. Under the expectation damage measure, the buyer will view reliance as a riskless investment since the return to reliance is protected in the event of a breach. Given the buyer's level of reliance, the seller's breach decision will still be the socially efficient choice, since a breach occurs only if $x_{s}{ }^{\prime}\left(a_{2}, \theta\right)-\delta_{E}>x_{s}{ }^{\prime}\left(a_{1}, \theta\right)$, or, by substituting in $\delta_{E}=x_{b}{ }^{\prime}\left(a_{1}, r\right)-x_{b}{ }^{\prime}\left(a_{2}, r\right)$, where:

$$
x_{s}{ }^{\prime}\left(a_{2}, \theta\right)+x_{b}{ }^{\prime}\left(a_{2}, r\right)>x_{s}{ }^{\prime}\left(a_{1}, \theta\right)+x_{b}{ }^{\prime}\left(a_{1}, r\right) \text {. }
$$

Therefore, the seller will breach under $\delta_{\mathrm{E}}$, as in the socially efficient case, only if $\theta>(11 / 4) r-(5 / 2) r^{2}$.

The buyer now chooses a reliance level which maximizes $E\left(x_{b}{ }^{\prime}(a, r)\right)$ given the seller's breach criterion. Since the buyer will receive the same payoff,

59. An approximate solution to this problem can be obtained numerically by iterating from $r=0$ to $r=1$ in steps of, for example, .001 , calculating for each $r$ the associated $\theta^{\prime}$, which also yields (since $\theta$ is uniformly distributed on $[0,1]) \operatorname{Pr}\left\{0 \leq \theta \leq \theta^{\prime}\right\}$, and then calculating the value of the expected joint payoff. The value of $r$ associated with the highest expected joint payoff is approximately $r$. 
$x_{b}{ }^{\prime}\left(a_{1}, r\right)$, regardless of whether the seller chooses $a_{1}$ or $a_{2}$, the buyer's reliance level will be $r=\hat{r}=.5$. This level of reliance will exceed the socially efficient level. With $r=.5$, the critical value of $\theta$ is .75, which is higher than that found under social efficiency. A higher $\theta^{\prime}$ implies that the seller will be induced to perform the contract more often than is socially efficient. This increased desire not to breach follows from the fact that the buyer's overreliance must be compensated in the event of seller breach.

3. Contracting under $\delta_{R}=\overline{x_{b}{ }^{\prime}}-x_{b}{ }^{\prime}\left(a_{2}, r\right)$. With $\delta_{\mathrm{R}}$, a breaching seller has only to restore the buyer to the "no contract" position, $\bar{x}_{b}$ ' $=.25$. Given a level of reliance $r$, the seller will maximize his utility by breaching only when -0.25 $-0.5 r>-2 \theta,{ }^{60}$ or, by simplifying, when $\theta>\theta^{\prime}=.25 r+.125$. Taking this condition into account, the buyer maximizes her expected utility by choosing $r$ (substituting $\delta_{\mathrm{R}}$ into equation (6)) such that:

$$
r=\underset{r^{\prime} \in R}{\operatorname{argmax}}\left(\operatorname{Pr}\left\{0 \leq \theta \leq \theta^{\prime}\right\}\right)\left(.5 r^{\prime}-5\left(r^{\prime}\right)^{2}\right)+\left(\operatorname{Pr}\left\{\theta^{\prime}<\theta \leq 1\right\}\right)(.25) .
$$

The solution to this problem is, approximately, $r=.589$. This induces a critical realization value of $\theta^{\prime}=.272 .^{61}$ Therefore, the level of reliance that the buyer will choose under $\delta_{\mathrm{R}}$ exceeds both the socially efficient and the expectation damage levels of reliance. This increase in reliance expenditure occurs because the buyer's expenditures are perfectly insured, and, furthermore, the buyer knows that by increasing the reliance level the seller's incentive to breach is reduced. From the buyer's viewpoint, her actions increase her utility because compliance is preferred.62 This differs from the $\delta_{\mathrm{E}}$ analysis where the buyer is indifferent between compliance and breach.

4. Contracting under $\delta_{E}{ }^{\prime}\left(r^{*}\right)=x_{b}{ }^{\prime}\left(a_{1}, r^{*}\right)-x_{b}{ }^{\prime}\left(a_{2}, r^{*}\right)$. In implementing the expectation damage measure to protect only efficient reliance expenditures, the $\delta_{\mathrm{E}}{ }^{\prime}$-efficient level of reliance must be calculated. By Proposition 1, the socially efficient level of reliance $r^{*}=.483$ is also the $\delta_{\mathrm{E}}{ }^{\prime}$-efficient level of reliance. Using $r^{*}=.483$ in the definition of $\delta_{\mathrm{E}}{ }^{\prime}$, the seller will choose to breach if $\theta>(11 / 4) r^{*}-(5 / 2)\left(r^{*}\right)^{2} .{ }^{63}$ This results in a breach for state realizations, $\theta>\theta^{\prime}=.745$. As shown above, this is the same as the socially optimal breach criterion. Furthermore, the buyer, in maximizing her expected return given that $\theta=.745$, will actually choose reliance expenditures such that $r=.483$. Therefore, the $\delta_{\mathrm{E}}$-efficient level contract achieves socially efficient reliance and breach, as stated in Proposition 2.

5. Contracting under $\delta_{R}{ }^{\prime}\left(r^{*}\right)=\overline{x_{b}}{ }^{\prime}-x_{b}{ }^{\prime}\left(a_{2}, r^{*}\right)$. In implementing $\delta_{\mathrm{R}}{ }^{\prime}$, the $\delta_{\mathrm{R}}{ }^{\prime}$ efficient level of reliance must be calculated. Assume that the court

60. This inequality is found by substituting into the breach criterion under $\delta_{\mathrm{R}}$.

61. Notice that $\theta^{\prime}$ under $\delta_{\mathrm{R}}$ is much lower than the socially efficient level. This indicates that under the reliance damage measure there will be excessive breach.

62. Shavell, supra note 1, at 480 ; see supra p. 93 (Assumption A1(iii)).

63. This is also the socially efficient breach criterion. 
announces that it will protect, using the reliance damage measure, reliance expenditures up to $r^{\prime}$. The seller will then breach the contract only if:

$$
x_{s}^{\prime}\left(a_{2}, \theta\right)-{\overline{x_{b}}}^{\prime}+x_{b}^{\prime}\left(a_{2}, r\right)>x_{s}\left(a_{1}, \theta\right) .{ }^{64}
$$

This condition implies that the seller will breach if:

$$
\theta>\theta^{\prime}=\left(\overline{x_{b}^{\prime}}+.5 r^{\prime}\right) / 2 \text {. }
$$

Given this breach criterion, the socially efficient level of reliance maximizes expected joint payoff

$$
\operatorname{Pr}\left\{0 \leq \theta \leq \theta^{\prime}\right\}\left[\mathrm{E}\left(-2 \theta \mid 0 \leq \theta \leq \theta^{\prime}\right)+5 \mathrm{r}^{\prime}-5\left(\mathrm{r}^{\prime}\right)^{2}\right]+\operatorname{Pr}\left\{\theta^{\prime}<\theta<1\right\}
$$

The $\delta_{R}$-efficient level of reliance is where $r^{\prime}$, the amount the courts are willing to protect, equals the socially efficient level of reliance when given court protection. For this example, the $\delta_{R}$ '-efficient level of reliance, $r^{\prime}$, is $r^{\prime}=.300$, and $\theta$, the critical realization value, is $\theta=0.2 .^{65}$ Given this breach criterion, the buyer will choose the $\delta_{R}{ }^{\prime}$-efficient level of reliance, 0.3 . This level of reliance is chosen because, as shown above, the buyer will have reliance expenditures compensated in the case of a breach up to the $\delta_{R}{ }^{\prime}$-efficient level.

\section{IV}

\section{Expectation As a Limit to Reliance}

It is commonplace in both the legal and economic literature to suggest that courts will not return reliance damages in excess of expectation damages: "[I]n suits for reliance damages, the expectation interest, if provable, represents a ceiling on the amount which can be recovered." 66 "Since the buyer will earn zero profit if a breach occurs, he must be guaranteed a positive profit if the contract is performed-otherwise he would not have entered into the contract . . . . [T]he damage payment under the reliance remedy is necessarily less than the buyer's benefit."67

In the case of incidental reliance, however, Fuller and Perdue have noted that the reliance damage measure may well exceed expectation damages: "[With respect to incidental reliance,] there appears no valid reason to limit the plaintiff's recovery by the expectation interest." 68

The model of contracting presented above lends support to this contention of Fuller and Perdue. Consider again the damage measures $\delta_{E}=$ $x_{b}{ }^{\prime}\left(a_{1}, r\right)-x_{b}{ }^{\prime}\left(a_{2}, r\right)$ and $\delta_{R}=\overline{x_{b}}-x_{b}{ }^{\prime}\left(a_{2}, r\right)$. While it is true that the buyer's willingness to enter into the contract implies that the first term of $\delta_{E}$ exceeds

64. This assumes that the buyer chooses reliance greater than or equal to $r^{\prime}$. Because of the definition of $\delta_{R}{ }^{\prime}$, the actual seller breach criterion is conditional on whether the buyer's reliance is greater or less than $r^{\prime}$. In calculating the $\delta_{k}$ '-efficient level of reliance, however, this nuance is immaterial, as the buyer will always choose the $\delta_{k}$-efficient level of reliance, given that this amount is protected by the court.

65. The $\delta_{\mathrm{R}}{ }^{\prime}$-efficient level of reliance can be numerically obtained by iterating from $r=0$ to $r=1$ in steps of, for example, .001, determining $\theta^{\prime}$ for each level of $r$, and then calculating the socially efficient level of reliance given $\theta^{\prime}$. The highest socially efficient level of reliance among those which equal the original $r$ is the $\delta_{k}$ '-efficient level of reliance.

66. J. Friedman, supra note 8, at 110.

67. Polinsky, Risk Sharing Through Breach of Contract Remedies, 12 J. LEgal Stud. 427, 435 (1983).

68. Fuller \& Perdue, supra note 1 , at 78. 
the first term of $\delta_{R}$, it does not necessarily follow that $\delta_{E}$ exceeds $\delta_{R}$. This is because the reliance level, $r$, differs between the two damage measures. Typically, the buyer's level of reliance under the reliance damage measure will exceed the level of reliance the buyer chooses under the expectation damage measure. ${ }^{69}$ Since, if damages are not paid, reliance expenditures lower buyer's utility in the event of breach, the second term of $\delta_{R}$ may be less than the second term of $\delta_{\mathrm{E}}$, and reliance damages would therefore exceed expectation damages.

The case for allowing reliance damages to exceed expectation damages is strengthened if the buyer's gross contract profit, $x_{b}{ }^{\prime}$, depends on the realized state of the uncertainty as well as on the seller's action and the buyer's reliance. The buyer's pre-damages utility would then be $x_{b}{ }^{\prime}=x_{b}{ }^{\prime}(a, r, \theta) .{ }^{70}$ (Similarly, the buyer's "no-contract position" could also be state-dependent: $\left.\bar{x}_{b}^{\prime}=\bar{x}_{b}^{\prime}(\theta)\right)$. With a state-dependent utility function, a bad state realization, from the buyer's point of view, may result in the buyer being better off if the seller does not perform the contract. However, if the buyer's no-contract position is not similarly adversely affected by the state realization, then restoring the buyer to her no-contract position may be more costly than protecting her expectation interest.

\section{$\mathrm{V}$ \\ Contracting Over and Measuring Reliance}

If courts protect only reasonable reliance, then reliance actions by themselves will pose no bar to efficient contracting. If, however, the court system is inefficient, either in creating an incentive to overrely or in insufficiently protecting reliance, it may be possible to include buyer's reliance actions in the contract terms. ${ }^{71}$ How difficult is it to contract over reliance actions? Many commentators are skeptical as to this possibility:

If contracts could be entered . . . in which each party's reliance could be completely specified, constructing an optimal contract would still pose no problem ... [But] the nature of a party's reliance may be complicated or render it difficult for the other party contractually to specify its nature, to monitor it, or even to calculate its optimal level. ${ }^{72}$

$[\mathrm{N}]$ egotiating over [the buyer's] reliance decision is not a simple matter. For example, if it is difficult for [the seller] to verify how much additional benefit [the buyer] would obtain from the additional reliance expenditure, [the buyer] might be able to take advantage of [the seller's] imperfect information. Thus[,] . . it is reasonable to consider the possibility that a provision regarding the reliance decision was not included in the contract. ${ }^{73}$

While the reservations expressed in the literature concerning the ability to contract over reliance actions are legitimate, it should be noted that such

69. See supra Part III.C; Shavell, supra note 1, at 480.

70. This is the approach taken in Leitzel, supra note 5, at 94.

71. In certain contracts, stipulated damages, if not acting as a penalty, may be allowed. See $\mathrm{E}$. FARNSWORTH, supra note 7 , at 895 .

72. Rogerson, supra note 1 , at 39 .

73. A. Polinsky, An Introduction to Law and Economics 33 (1983). 
concerns are also applicable to many other contractual terms. Contractual incompleteness and imperfect information are problems common to many contract formations. Unique attributes of reliance actions that render them particularly non-contractible are not obvious.

After a breach, are reliance damages or expectations damages easier to implement? Most commentators side with reliance damages. Reliance actions have already been taken by the buyer and may be easily verified. ${ }^{74}$ In contrast, contract expectations were necessarily frustrated by the breach and therefore have to be inferred. Nevertheless, the literature is not in total agreement on this point. An expectation measure might be chosen over a reliance measure because "it is usually easier to establish in court the value of performance than the extent of reliance."75

Both the ability to contract over reliance actions and the ability to establish the amount of reliance in court may be moot points if the courts are inefficient at enforcing contracts. This point is stressed by economic analyses in the New Institutional tradition. ${ }^{76}$ Oliver Williamson, a leading figure in the New Institutional Economics, utilizes an extreme assumption in a recent book: Court ordering is efficacious, except in the presence of reliance ("asset specificity"), whereupon court ordering breaks down. ${ }^{77}$ While court ordering can indeed be inefficient, it is again not clear what unique feature of reliance actions makes them particularly difficult to enforce.

Economic analyses in the law and economics literature often assume that all reliance is protected, thereby creating an incentive to overrely. In contrast, the analyses in the New Institutional Economics assume that courts are incapable of correctly protecting reliance, and this inability generally results in underreliance or alternative means of arranging transactions. The legal reality seems to be somewhere in the middle. Courts are not completely efficient, but they make efforts to protect reasonable reliance, which reduces incentives to overrely and reduces the need for alternative governance mechanisms.

\section{VI \\ Conclusion}

The legal and economic approaches to reliance actions differ in many respects. Perhaps the most important difference stems from the interpretation of the protection of reliance in the event of a breach. The legal

74. See, e.g., id. at 35 .

75. Cooter \& Eisenberg, supra note 1, at 1461 .

76. The New Institutional Economics focuses on transactions costs and the governance structures that arise in order to minimize them. See, e.g., O. Williamson, The Economic Institutions of Capitalism: Firms, Markets, Relational Contracting (1985); O. Williamson, Markets \& Hierarchies: Analysis \& Antitrust Implications (1975); Klein \& Leffler, The Role of Market Forces in Assuring Contractual Performance, 89 J. PoL. ECoN. 615 (1981).

77. O. Williamson, Economic Institutions, supra note 76 , at 32 . On the connection between reliance and asset specificity, see Leitzel, The New Institutional Economics and a Model of Contract, $11 \mathrm{~J}$. ECon. Behav. \& Orc. 75 (1989). 
literature notes that courts will not protect unreasonable amounts of reliance. In contrast, economic analyses have assumed that all reliance is protected. This article has shown that the circularity involved in protecting reasonable reliance may be overcome; hence, the reasonableness standard may be operational and incorporated into the economic models of reliance.

In addition to the protection of reliance, this article has examined the legal and economic approaches to other aspects of reliance: (1) the definition of reliance; (2) expectation damages as a limit to reliance damages; and (3) contracting over and measuring reliance. Legal and economic analyses often differ on these issues. A recognition of these differences may prove beneficial to law and economics in future research. 


\section{APPENDix A}

\section{Proof of Lemma 1}

Assume that the seller will never breach $\left(a=a_{1}\right)$. Then equation (2) will reduce to $r^{*}=\hat{r}=\underset{r^{\prime} \in R}{\operatorname{argmax}} E\left[x_{b}{ }^{\prime}\left(a_{1}, r^{\prime}\right)+x_{s}{ }^{\prime}\left(a_{1}, \theta\right)\right]$. Since only the first term of this expression depends on the buyer's reliance level, the expression is maximized by the buyer's optimal reliance given $a_{1}$. The optimal reliance level for the buyer, given that $a=a_{1}$, will be the level where the buyer's utility is no longer increased by spending more on reliance. By Assumption Al (i), this level of reliance is $\hat{r}$.

Now consider the situation where the seller's optimal action plan $a^{\prime}(r, \theta)$ involves some breach. Under this situation $r^{*}=\operatorname{argmax} E\left[x_{b}{ }^{\prime}\left(a^{\prime}, r^{\prime}\right)+x_{s}{ }^{\prime}\left(a^{\prime}\right.\right.$, $r^{\prime} \in R$

$\theta)$ ], and again the second term of the expression is independent of $r$. The first term of this expression cannot be maximized by any $r>\hat{r}$, since $\hat{r}$ maximizes the expression if there is no breach (Assumption Al (i)), and, by Assumption Al (ii), higher reliance levels result in a lower buyer payoff if there is a seller breach. Therefore, $r^{*} \leq \hat{r}$. 


\section{APPENDIX B}

\section{Proof of Proposition 1}

Assume that, under $\delta_{\mathrm{E}}^{\prime}$, the court offers to protect the reliance expenditures of the buyer up to the socially efficient level of reliance $r^{*}$. Assume further, for the moment, that the buyer actually chooses reliance level $r^{*}$. The seller then will choose to breach with action $a_{2}$ in states $\theta$ where $x_{s}{ }^{\prime}$ $\left(a_{2}, \theta\right)-\delta_{E}{ }^{\prime}\left(r^{*}\right)>x_{s}{ }^{\prime}\left(a_{1}, \theta\right)$ or where $x_{s}{ }^{\prime}\left(a_{2}, \theta\right)-x_{b}{ }^{\prime}\left(a_{1}, r^{*}\right)+x_{b}{ }^{\prime}\left(a_{2}, r^{*}\right)>x_{s}{ }^{\prime}$ $\left(a_{1}, \theta\right)$. This implies that the seller will breach when $x_{s}^{\prime}\left(a_{2}, \theta\right)+x_{b}{ }^{\prime}\left(a_{2}, r^{*}\right)>$ $x_{s}^{\prime}\left(a_{1}, \theta\right)+x_{b}^{\prime}\left(a_{1}, r^{*}\right)$, which is the same as the socially efficient breach criterion implicit in equation (1). Therefore, the seller's action choices under $\delta_{E}^{\prime}\left(r^{*}\right)$ are the same as the socially efficient action choices. (Condition (7), which characterizes the $\delta_{E}^{\prime}\left(r^{*}\right)$-efficient level of reliance, is the same as condition (2), which defines $r^{*}$.) Therefore, $r^{*}$ is a fixed point of the reliance mapping.

So far the proof has been carried out under the assumption that the buyer will actually choose the reliance level equal to $r^{*}$. It will now be demonstrated that this is the actual level of reliance that will be chosen by the buyer. Consider a level of reliance $r<r^{*}$. For reliance in this range, $\delta_{E}{ }^{\prime}\left(r^{*}\right)$ must give the buyer the same payoff as if the contract were completed, $x_{b}{ }^{\prime}\left(a_{1}, r\right)$, whether the seller chooses $a_{1}$ or $a_{2}$, since the return to all reliance is protected if $r<r^{*}$. However, from Lemma 1 , payoff $x_{b}{ }^{\prime}\left(a_{1}, r\right)$ is necessarily increasing in $r$ for $r<r^{*}$. The buyer can thus raise her payoff by increasing her reliance level. Since this argument holds for all $r<r^{*}$, the buyer will never choose a level of reliance less than $r^{*}$.

Now consider a buyer reliance level, $r$, such that $r \geq r^{*}$. In this range, by the definition of $\delta_{E}^{\prime}\left(r^{*}\right)$, damages for a breach will be independent of the $r$ actually chosen because the damages are based on $r^{*}$. It follows that the seller's payoff will also be independent of $r$ in this range and will instead be based on $r^{*}$. The buyer's choice of reliance, $r$, which will maximize her expected payoff, will then also maximize the social payoff (with the seller's payoff constant as $r$ changes). Since $r^{*}$ is the level of reliance that will maximize the social payoff given the socially efficient breach criterion, which $\delta_{E}^{\prime}\left(r^{*}\right)$ provides, the buyer will choose $r^{*}$. 


\section{APPENDIX C \\ Proof of Proposition 2}

The proof to Proposition 1 noted that the seller's actions under $\delta_{\mathrm{E}}{ }^{\prime}$ are efficient given the buyer's reliance, and that the buyer will choose $r^{*}$ given the seller's choices and $\delta_{\mathrm{E}}$ '. Therefore, the seller's actions and the buyer's reliance are characterized by Conditions (1) and (2), which yield the socially efficient solutions. 
